\title{
Substrate Temperature Dependence of Crystalline Microstructure for CoCrTa Films
}

H. Tamai and K. Tagami (Microelectronics Res. Labs., NEC Corporation)

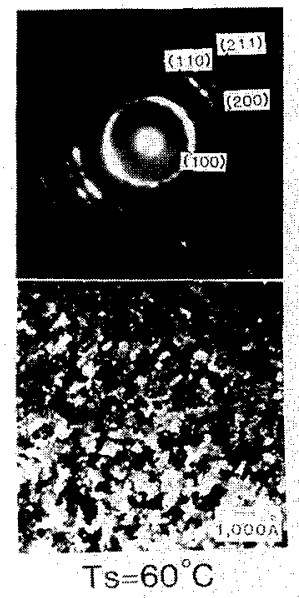

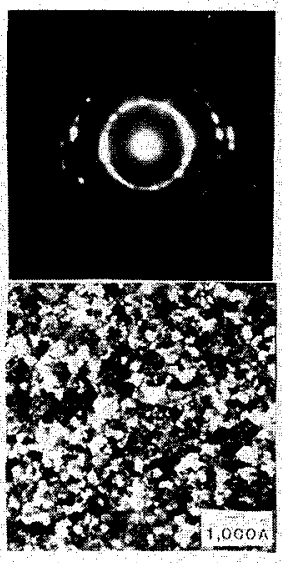

TS $=100^{\circ} \mathrm{C}$

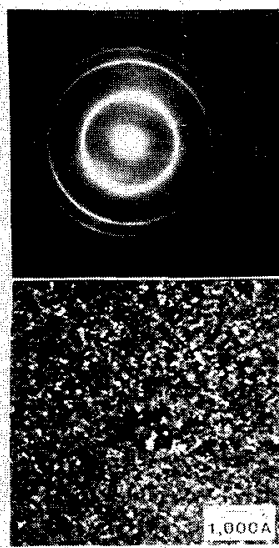

$\mathrm{TS}=140^{\circ} \mathrm{C}$

CoCrTa(2at\%Ta, $17 \mathrm{at} \% \mathrm{Cr})$

These photographs show transmission electron diffraction patterns and TEM micrographs for CoCrTa films, which were deposited under differing substrate temperature Ts $\left(60^{\circ} \mathrm{C}\right.$, $100^{\circ} \mathrm{C}$ and $140^{\circ} \mathrm{C}$ ). Diffraction patterns, such as (100), (110) and (200), are observed for the hcp-Co planes. Crystalline grain sizes decrease with increasing Ts. Furthermore, perpendicular anisotropy field $\mathrm{Hk}$ and perpendicular coercivity $\mathrm{Hc}_{\perp}$ values increase with increasing $T$ s. A fine grain structure with good c-axis orientation and high Hc/ are obtained by the addition of $\mathrm{Ta}$ to $\mathrm{CoCr}$ films under high Ts.

[Ref] M.Naoe and M.Matsuoka, J. Appl. Phys., 57(1) (1985) 4019.

H.Tamai, et al., Abstract of Annual Conf. of Magn. Soc. of Jpn., (1988) 3aC-2.

H.Tagami, et al., IEEE Trans. Magn., MAG-24, (1988) 2347. 